\title{
Pyogenic Ventriculitis Associated with Urosepsis: A Rare Case Report
}

\author{
Joana Correia Lopes ${ }^{1}$, Andreia Sofia Basílio², Mário Amaro ${ }^{1}$ \\ ${ }^{1}$ Internal Medicine Department, Hospital Garcia de Orta EPE, Almada, Portugal \\ ${ }^{2}$ Centro de Saúde de Santo António, SESARAM EPERAM, Funchal, Portugal
}

Received: $28 / 11 / 2020$

Accepted: 01/12/2020

Published: $23 / 12 / 2020$

How to cite this article: Correia Lopes J, Basílio AS, Amaro M. Pyogenic ventriculitis associated with urosepsis: a rare case report. EJCRIM 2020;7: doi:10.12890/2020_002178.

Conflicts of Interests: The Authors declare that there are no competing interests.

This article is licensed under a Commons Attribution Non-Commercial 4.0 License

\section{ABSTRACT}

Pyogenic ventriculitis is an infection of the cerebral ventricles usually associated with neurosurgery or head trauma. There are less than 10 reported cases of community-acquired pyogenic ventriculitis in adults. We present the case of a 71-year-old man with a medical history of type 2 diabetes mellitus, hospitalized due to urosepsis caused by $E$. coli. Because he had a fluctuant level of consciousness, he underwent magnetic resonance imaging that diagnosed pyogenic ventriculitis. He was treated with ceftriaxone $2 \mathrm{~g} 12 / 12 \mathrm{~h}$ for a total of 6 weeks and recovered without neurological deficits. Pyogenic ventriculitis is a clinical challenge due to its rarity, atypical presentation and variety of aetiological microorganisms.

\section{LEARNING POINTS}

- Pyogenic ventriculitis is an infection of the cerebral ventricles usually associated with neurosurgery or head trauma; communityacquired primary pyogenic ventriculitis is very rare.

- Presentation is atypical (no meningism), multiple microorganisms can be involved, and it should be treated with prolonged antibiotic regimens.

- $\mathrm{MRI}$ is the most useful exam for diagnosis.

\section{KEYWORDS}

Pyogenic ventriculitis, urosepsis, E. coli

\section{CASE DESCRIPTION}

We present the case of a 71-year-old male patient, still professionally active, with a medical history of type 2 diabetes mellitus with poor metabolic control, who was admitted to the emergency department with symptoms of nausea, vomiting, dysuria and fever. A diagnosis of pyelonephritis was made and the patient was discharged with a prescription for amoxicillin-clavulanic acid. Over the next few days, in addition to the previous symptoms, a change in the patient's behaviour and cognition was noticed, so he returned to hospital. At this second presentation, he was confused and had a fever (temperature $39^{\circ} \mathrm{C}$ ), but there were no other abnormalities in his physical examination, as there was no alteration in his cardio-pulmonary auscultation, no neurological deficits and no meningeal signs. He denied any recent travel, head trauma or previous neurosurgery. His laboratory results revealed leucocytosis, elevated C-reactive protein, altered renal function and leukocyturia (Table 1). A renal CT scan showed kidneys with multiple simple cysts and inflammatory signs. While in the emergency department, the patient's level of consciousness declined from a Glasgow Coma Scale (GCS) score of 14 to 7, so he was admitted to the internal medicine department with a diagnosis of urosepsis and was prescribed ceftriaxone $2 \mathrm{~g}, 24 / 24 \mathrm{~h}$. 


\begin{tabular}{|l|l|}
\hline Haemoglobin & $140 \mathrm{~g} / \mathrm{l}$ \\
\hline Platelet count & $91 \times 10^{9} / \mathrm{l}$ \\
\hline White blood cell count & $21.8 \times 10^{9} / \mathrm{I}(94 \%$ neutrophils) \\
\hline Glucose & $97 \mathrm{mg} / \mathrm{dl}$ \\
\hline Urea & $100 \mathrm{mg} / \mathrm{dl}$ \\
\hline Creatinine & $3.0 \mathrm{mg} / \mathrm{dl}$ \\
\hline Sodium & $136 \mathrm{mmol} / \mathrm{l}$ \\
\hline Potassium & $4.5 \mathrm{mmol} / \mathrm{l}$ \\
\hline CRP & $45.18 \mathrm{mg} / \mathrm{dl}$ \\
\hline HIV 1 and 2 & Negative \\
\hline Urinalysis & 500 leukocytes/Ml; negative nitrite \\
\hline
\end{tabular}

Table 1. Blood tests at admission to the emergency room

In his first days in hospital, he was agitated and disoriented but his physical examination showed no new findings and he was apyretic. There was a slow reduction in inflammatory parameters and a multisensitive E. coli grew in blood and urine cultures.

By the fourth day of hospitalization, the fever had returned and his mental status became fluctuant: one hour he had a GCS score of 14 and the next hour he had a GCS score of 7. His physical examination revealed new nuchal and inferior member rigidity, so a lumbar puncture was performed (Table 2) and a cranial CT scan was ordered. The CT scan had no relevant alterations, so we proceeded to an MRI. This latter exam showed purulent collections in the lateral ventricles and occipital horns suggestive of pyogenic ventriculitis (Fig. 1).

\begin{tabular}{|l|l|}
\hline Aspect & Clear \\
\hline Total protein & $82 \mathrm{mg} / \mathrm{dl}$ \\
\hline Glucose & $76 \mathrm{mg} / \mathrm{dl}$ \\
\hline Blood glucose at the time & $300 \mathrm{mg} / \mathrm{dl}$ \\
\hline Cell count & $\begin{array}{l}24 \text { cells/ } / \mathrm{l} \\
\text { (mononuclear cells } \\
\text { predominantly) }\end{array}$ \\
\hline Culture & Sterile \\
\hline Sodium & $136 \mathrm{mmol} / \mathrm{l}$ \\
\hline
\end{tabular}

Table 2. Cerebrospinal fluid analysis

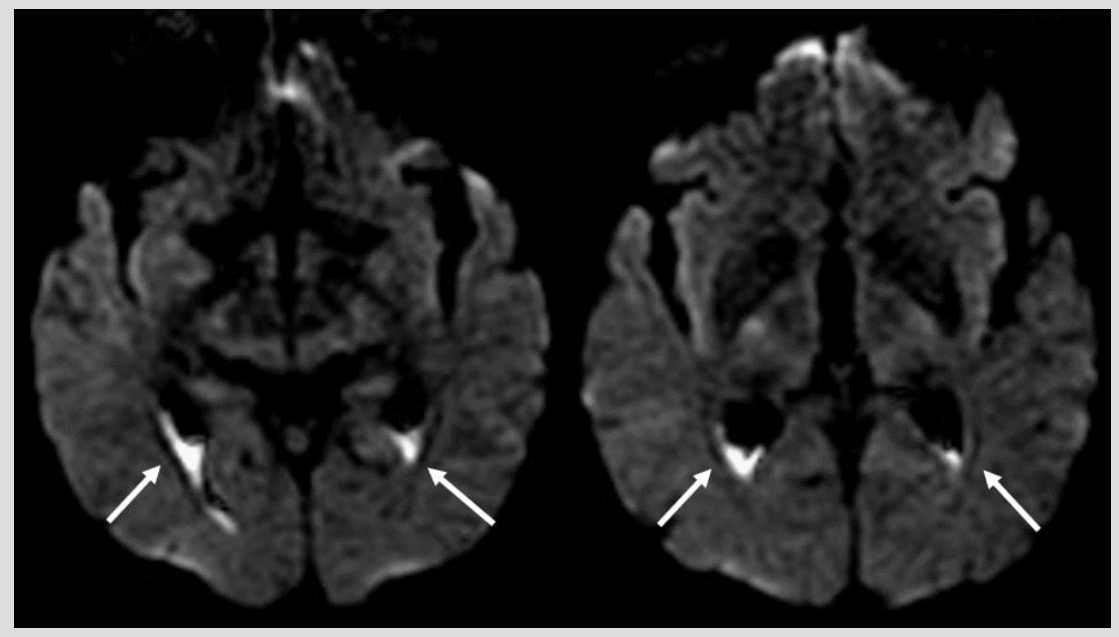

Figure 1 Magnetic resonance imaging, DWI sequences (arrows point to the pus in the ventricles)

A multidisciplinary discussion followed, and it was decided that the patient did not need surgery as there was no hydrocephaly, but that the antibiotic regimen should be changed to ceftriaxone $2 \mathrm{~g}, 12 / 12 \mathrm{~h}$. A transoesophageal echocardiogram ruled out endocarditis as a septic emboli source.

On the 25th day, the MRI was repeated and showed the purulent foci were significantly smaller. The antibiotic regimen was maintained for 6 weeks and by the end of this period the patient was oriented, still a little confused, but well enough to be discharged. A long and difficult rehabilitation process followed, but 6 months after discharge the patient had returned to his previous autonomy with no neurological sequelae. As a new physical finding, he presented Beau lines in his finger nails (Fig. 2). 


\section{DISCUSSION}

Pyogenic ventriculitis is a bacterial infection of the cerebral ventricles more commonly associated with head trauma or neurosurgery and neurosurgical devices. Although rare, it can also present as a complication of meningitis or cerebral abscess in adults. To date less than 10 cases of adult community-acquired primary pyogenic ventriculitis have been published, all in the last 10 years, probably because of the increasing use of MRI ${ }^{[1]}$.

Primary pyogenic ventriculitis cases appear to be more common in the elderly (mean age of 65 years) and to present with no meningism ${ }^{[1,2]}$. In all published cases, MRI was essential for the diagnosis and CT scans were normal or had ventricle collections that could not be differentiated between blood and pus. Bacterial agents were varied as were the antibiotic regimens chosen, and some patients needed neurosurgical drainage ${ }^{[2]}$. Diabetes seems to be a common risk factor owing to its immunosuppressive role ${ }^{[3]}$.

MRI is the most useful exam in the diagnosis of pyogenic ventriculitis, with the most characteristic finding being the presence of purulent debris with an irregular outline in the interior of the cerebral ventricles. This material presents as hyperintense in T1 sequences and hypointense in $\mathrm{T} 2$ sequences, but it is even more evident in diffusion-weighted imaging (DWI) sequences ${ }^{[3]}$.

In a literature review, we found only two cases similar to that presented here. In both these cases the initial diagnosis was urinary infection, but an altered mental status led to a subsequent study, with pyogenic ventriculitis being diagnosed. As in our case, E. coli was the bacterial agent implied as it grew on blood, urine and cerebrospinal fluid cultures ${ }^{[4,5]}$. We could only isolate $E$. coli in blood and urine cultures, probably because the patient was already on his fifth day of antibiotic, so we think it is reasonable to assume that the agent responsible for the pyogenic ventriculitis was E. coli.

We used an antibiotic regimen of ceftriaxone $2 \mathrm{~g}, 12 / 12 \mathrm{~h}$ (the so called 'meningeal dose') for 6 weeks, even though there were no clinical guidelines to support it. In the two cases similar to ours, this was also the antibiotic regimen chosen, also with a good outcome $[4,5]$. The few cases published and the multitude of microorganisms implicated make it difficult to generate a universal recommendation, but the consensus seems to be to use long antibiotic regimens ${ }^{[1,6]}$.

The atypical clinical manifestations and variety of bacterial organisms involved make suspicion of pyogenic ventriculitis less likely. In a patient with an altered mental status, MRI is the most useful exam to diagnose this clinical condition as it shows specific abnormalities that cannot be differentiated in a CT scan ${ }^{[1-3,5]}$.

\section{REFERENCES}

1. Lesourd A, Magne N, Soares A, Lemaitre C, Taha M-K, Gueit I, et al. Primary bacterial ventriculitis in adults, an emergent diagnosis challenge: report of a meningoccal case and review of the literature. BMC Infect Dis 2018;18:226.

2. Gronthoud F, Hassan I, Newton P. Primary pyogenic ventriculitis caused by Neisseria meningitidis: case report and review of the literature. JMM Case Rep 2017;4(1):e005078.

3. Fukui M, Williams R, Mudigonda S. CT and MR imaging features of pyogenic ventriculitis. Am J Neuroradiol 2001;22:1510-1516.

4. Kobayashi H, Suzuki T, Tokuda Y. Pyogenic ventriculitis following urosepsis caused by Escherichia coli. BMJ Case Rep 2013;2013:bcr2013201148.

5. Ribeiro B, Bishop P, Jalili S. When a stroke is not just a stroke: Escherichia coli meningitis with ventriculitis and vasculitis: a case report. $J$ Crit Care Med 2020;6(1):69-75.

6. Kasimahanti R, Satish S, Anand M. Community-acquired Escherichia coli meningitis with ventriculitis in an adult-a rare case report. J Intensive Care 2018;6:63. 